\title{
SEX RATIO AND UNISEXUAL STERILITY IN HYBRID ANIMALS.
}

\author{
Bx J. B. S. HALDANE, M.A. \\ Fellow of New College, Oxford.
}

Many observers have noted that the crossing of different animal species produces an offspring one sex of which is rare or absent, or if present sterile, whilst occasionally the missing sex is represented by intermediate forms. Doncaster(1) concluded that the missing sex was gencrally the female, but, as will be shown later, this is by no means always the case. I believe, however, that the following rule applies to all cases so far observed, with one certain, and a few doubthinl exceptions :-

When in the $F_{1}$ offspring of two different animal races one sex is absent, rare, or sterile, that sex is the heterozygous sex.

By the heterozygous sex is meant that sex which is known to be heterozygons for sex factors and sex-linked factors, to contain an odd pair or an odd number of chromosomes, and to produce two different classes of gametes, which normally determine the sex of the offspring. The heterozygons or digametic sex is in most groups the male, but in birds and Lepidoptera the female. Gromps in which the male sex is haploid are only extreme cases of the normal type, in that all the chromosomes here behave like the sex-chromosomes of other groups.

Disturbances of sex-ratio and unisexual sterility have been observed as the result of crosses in Lepidoptera, Aves, Diptera, Mammalia, Anophra, and Cladocera. I have here recorded all cases known to me in which $(a)$ the animals were bred in captivity; $(b)$ more than 10 offspring were raised, and (c) one sex was absent or sterile, or the sexratio was more than $2: 1$. In the tables $F^{\prime}$ denotes fertility, $S$ sterility established by testing several individnals. Of course the fertility is often subnormal.

Table I summarizes the data for Lepidoptera. Goldschmidt's results were each obtained with several different races. In the other crosses there were 24 cases where females were absent or rare, 10 where males were fertile and females sterile, and a number where there was an 


\section{Sex Ratio and Unisexual Steritity in Hybrid Animals}

unstated excess of males; or else the males, though not known to have been fertile, were anatomically normal, whilst the females were clearly sterile.

Of exceptions to the rule there is first the case described by Goldschmidt(20) where crosses between two races of Lymantria gave

\section{TABLE I.}

\section{Lepidoptera.}

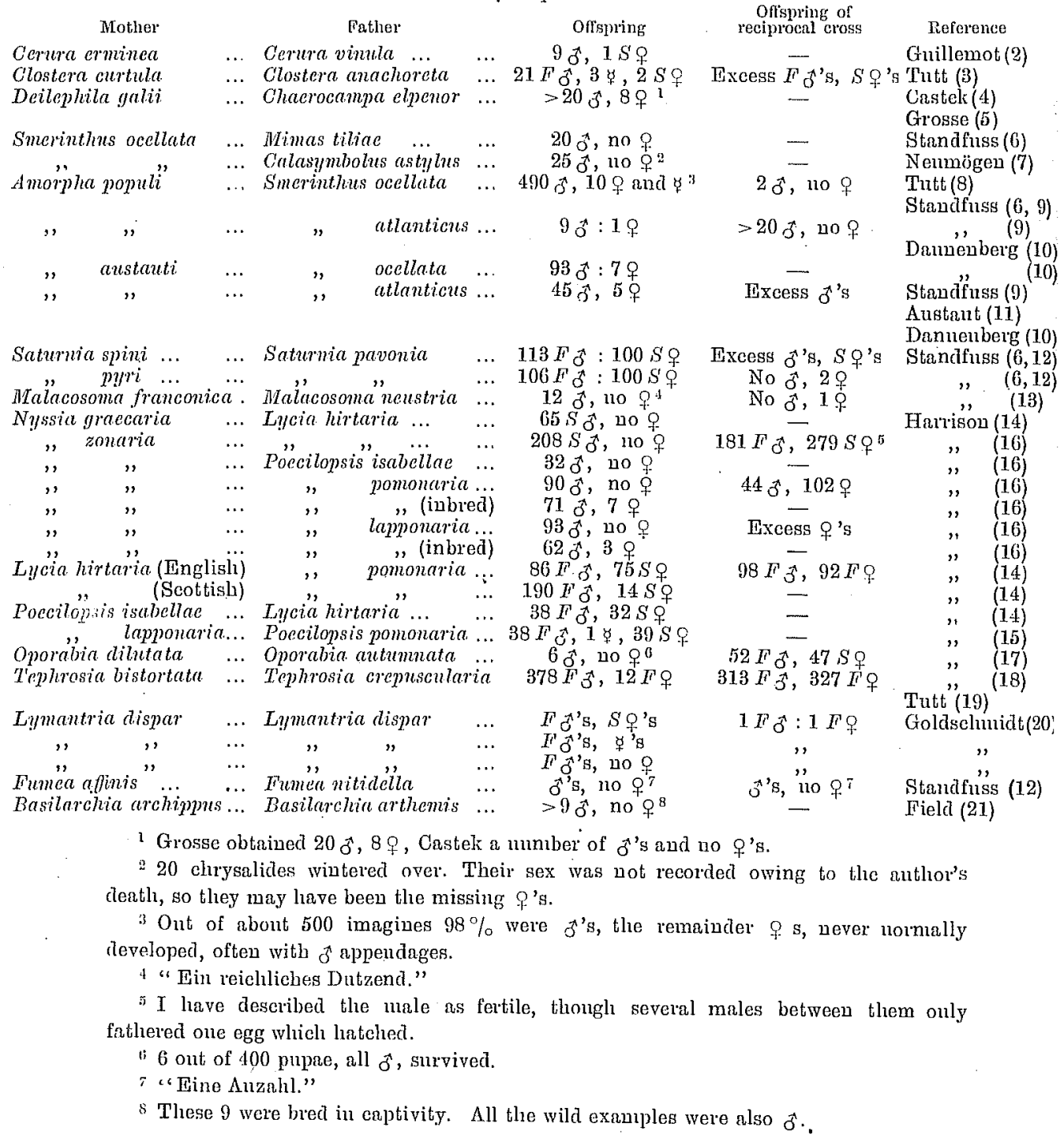


intersexual males, and an excess of males. This took place in two broods only. Goldschmidt's other intersexual males occurred either sporadically or in generations later than $F_{1}$, and are therefore not exceptions. It seems just possible that the intersexuality of the two aberrant broods may have been due to disease or other external conditions, or to unsuspected heterozygosis of one parent. His theoretical explanation of them is not convincing; since he ascribes to the race "Fukuoka" on p. 103 (loc. cit.) a formula which, nccording to the analysis on p. 66, is entirely inconsistent with its being a "realk" race as stated on p. 12 and borne out by its behaviour in other crosses.

In two of Harrison's reciprocal crosses noted in the table there was a moderate excess of females, though in one of them these females were sterile. Standfuss $(6,12)$ mentions five cases where a species-cross gave only females. In three of these the numbers of females recorded werc two, one, and one, which are insignificant; one (Drepana falcataria $q \times D$. curvatula $\left.\delta^{\prime}\right)$ was subsequently shown by him to give both sexes in equal numbers. In the last (Malacosoma castrensis $q \times$ neustria of) Bacot(22) found that the males emerged a year after the females, but in only slightly smaller numbers.

Finally Fletcher(23) obtained a brood of 33 females and no males from a Cymatophora or $\$$, supposed to have been fertilized by a $C$. ocularis $\delta$, but he was himself dubious of their paternity. There are thus no undoubted exceptions outiside Lymantria.

The data for Aves are summarized in Table II.

TABLE II.

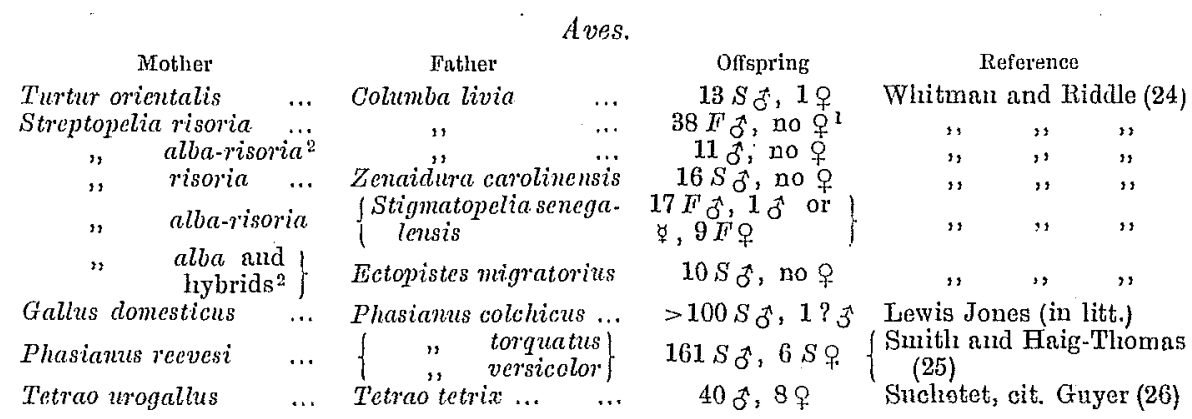

Besides these crosses many have been made, giving smaller numbers, or less aberrant sex-ratios. They are described by the authorities cited

1 One male begot a few living young, most were sterile.

* Alba and risoria yield fertile hybrids with normal sex-ratio. It therefore seems legitimate to include crosses of such hybrids along with crosses of pure species. 


\section{Sex Ratio and Unisexual Sterility in Hybrid Animals}

above, and Phillips(27). With regard to unisexual sterility the evidence is not clear. Whitman and Riddle(24) report one case (Columba livia $\$ \times$ Turtur orientalis $\sigma^{7}$ ) which gave two fertile males and one sterile female with rudimentary ovaries, and four cases where the males were fertile, and the females not known to be so, though not apparently proved sterile. The only possible exception is the cross of Turtur orientalis $q \times T$. turtur $\delta$, which gave 7 males and 14 females, all fertile. This may be compared with some of Harrison's cases which gave a moderate excess of females.

In Diptera the male is heterozygous. The data for the only recorded cross are given below, from Sturtevant(28).

Drosophila melanogaster $q \times D$. simulans $\delta$ gave $2 \gamma$, 3552 \% , the reciprocal 588 ơ, 171 q.

Drosophila melanogaster $X X Y$ $+\times D$. simulans $\sigma^{\lambda}$ gave 59 ð, $128 q$.

All these hybrids were sterile. The males produced from $X X Y$ q's were shown genetically to contain a simulans $X$ like those of the reciprocal cross. These latter all die in some families, but all or almost all survive in others, the difference perhaps depending on the simulans parent. Thus, though one cross often gives an excess of males, there is a far greater excess of females in the reciprocal, the two recorded males being perhaps non-disjunctional exceptions.

The data with regard to mammals, where again the male is heterozygous, are given in Table III.

TABLE III.

\section{Mammalia.}

$\begin{array}{cc}\text { Moṭler } \\ \text { Cavia porcellus } \\ \text { Bos indions } \\ \text { ", }, \text {, } & \ldots \\ \text { ", taurus } & \ldots \\ \text {, , , } & \ldots\end{array}$

\begin{tabular}{|c|c|c|c|}
\hline Father & & Offspring. & Reference \\
\hline Cavia rufescens & & $14 S \AA, 23 F$. & Detlefsen ( 29 ) \\
\hline Bibos frontalis & & $19 S \mathrm{o}, F q^{\prime} \mathrm{s}$ & Kuhn ${ }^{1}$ \\
\hline " sondaieus & & $1 s \neq$ & $" 3$ \\
\hline $\begin{array}{c}\text { grunniens } \\
\text { Bison antericanus }\end{array}$ & & 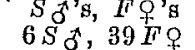 & Boyd (30) \\
\hline , bonasus & & $1 S \delta, 3 F \phi$ & Imanow (31) \\
\hline
\end{tabular}

Here the males are always sterile, and sometimes rare. This sterility and paucity may persist after one or more generations of back-crossing. Thus in the guinea-pig cross the $F_{1}$ females with porcellus males gave $31 S \delta, 52 F+$, and it was only in the next generation that a few of the males proved fertilc. Similarly 19 yak-cow male hybrids containing $\frac{1}{8}, \frac{1}{4}, \frac{1}{2}, \frac{3}{4}$, and $\frac{7}{8}$ cow "blood" were all sterile, and three out of four males containing $\frac{1}{4}$ bison blood were sterile. Mammalian crosses sometimes give small excesses of males, not exceeding $30 \%$. Bufion (33)

\footnotetext{
a Quoted by Detlefsen (29) and Ackermann (32).
} 
states that he obtained 7 males and 2 females from Ovis aries $q \times$ Capra lircus $\delta$, but this has never been confirmed:

In Anoplura the method of sex-determination is unknown. Keilin and Nuttall(34) found that Pediculus corporis $\$ \times P$. capitis $\delta$ gave $310 \varnothing, 12 \not, 107 q$, whilst the reciprocal cross gave $242 \%, 187 q$. The normal sex rates for $P$. corporis is $144 \delta^{\gamma}: 100 q$. The increased excess of males suggests that sex-determination is here perhaps on avian and lepidopteran lines, the female being heterozygous.

In Cladocera there seems to be no obvious cytological difference between the sexes. Dophnia obtusa $+\times D$. pulex $\delta$ was found by $\Delta$ gar.(35) to give a great excess of sexual broods and males (all sterile) among the descendants by parthenogenesis of the single original female hybrid. As these disturbances did not occur in the first generation they are not really comparable with the other cases cited.

Thus, with the exception of Goldschmidt's intersexual male families the rule always holds as regards sterility, while in the rare cases where an excess of the heterozygous sex is produced the reciprocal cross always gives a greater excess of the homozygotes.

As pointed out by Sturtevant(28) the excess of homozygotes may be due to two distinct processes, a killing-off of the heterozygotes, or their transformation into members of the normally homozygous sex. In Drosoplila the missing males die as larvae, on the other hand both Goldschmidt and Harrison have shown that in certain moth hybrids partial or complete transformation occurs. If the generalization of this paper is more than a mere coincidence it must be shown how these two effects, and also sterility, may be explained as due to the same cause.

Goldschmidt and Harrison have shown that many of their results can be explained by difference of intensity of the sex factors carried by the $Z$ or $X$ chromosomes in the two parental species. In Drosophila at least the other chromosomes play a part as well. In the pure races these factors are balanced by the cytoplasm or $W$ chromosome, but in the hybrids there is a lack of balance. This will be most serious in the heterozygous sex, since in the homozygotes the effect of the two $Z$ or $X$ chromosomes will be the average of the parental values. The heterozygotes will tend to be pushed either towards the homozygous sex or towards an exaggeration of their own sex. Either of these effects in moderation may be expected to cause sterility, as pointed out by Harison. The former may cause gynandromorphism, sex-reversal, or death when pushed further; the latter only death. Thus where both 


\section{Sex Ratio and Unisexual Sterility in Hybrid Animals}

reciprocal crosses yield males only, as in Fumea, we may suppose that in one case some of the males are transformed females as in Lymantria, whilst in the other the zygotes with an exaggerated tendency to maleness have died. This hypothesis may be compared with the demonstration by Bridges(36) that in Drosophila melanogaster both supermales with one $X$ chromosome and 3 sets of autosomes and superfemales with $3 \dot{X}$ 's and 2 sets of autosomes are sterile and not very viable.

But since in some cases the heterozygutes are transformed, in others killed off, alteration of sex-potential must have different effects in different animals. That this should be so is intelligible when we consider the great difference between the effects of castration or parabiosis in different groups. In Lepidoptera these conditions have little or no effect on somatic development, in mammals a great deal. The case here is by no means parallel, since the somatic cells are affected directly and not through an internal secretion, but the analogy shows that we need not expect the same effect from the same cause in different groups.

Although the explanation in terms of sex factors is attractive we have no satisfactory evidence of their existence. If sex is due simply to a double dose of a factor in the $X$ chromosome (or sex-linked factor group) we should expect this factor occasionally to mutate like its neighbours. This would lead, if the factor were lost in mammals or Diptera, to the production of males with two $X$ chromosomes and two sets of sex-linked factors, which would now exhibit partial and not complete sex-linkage. But such a condition has never been observed.

Moreover, upsets of the sex-ratio similar to those found in species crosses have been recorded in which factors which are certainly not sex factors are involved. Examples from Drosophila are given in Table IV.

The missing males are not transformed, but die as embryos. The char"acters concerned are all sex-linked recessives to the normal, "glazed" and "rugose" being multiple allelomorphs. They appear in the normal

\section{TABLE TV.}

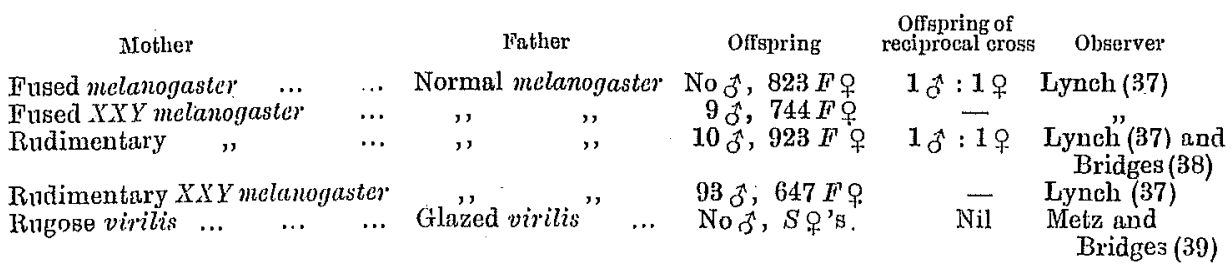


sex-ratio when the mother is a wild type heterozygote, but in each case the recessive female is almost wholly sterile. However "rudimentary" females have given $7 q$ and $13 \delta$ offspring with rudimentary males, so the upset of the sex-ratio is conditioned by crossing. The analogy with species crosses is striking, and may throw light on them. Two autosomal recessives in melanogtester, "morulit" and "dwarf," behave similarly, except that with morula and dwarf males the recessive females have given $2 q$ and $7 q$ respectively, with no males. Finally according to Doncaster (40) colour-blind men have an excess of diughters by normal women. Although the datil here are not so satisfactory, there is no sterility in the recessives.

Entia non sunt multiplicanda praeter necessitatem, and if ordinary factors, either sex-linked, like "rudimentary," or au tosomal like "morula," can cause the disappearance of the heterozygous sex in crosses, we lave no right to postulate sex factors for this purpose. A possible explanation of the phenomena under discussion is then as follows. In the course of the evolution of a species factorial differences arise between it and its parent species. They are perpetuated, probably by natural selection. Some of these factors, like "rudimentary," cause the death (or transformation) of the heterozygous sex when the new form is crossed with the ancestral. How this happens is quite obscure, but such factor's do exist, whereas sex factors, though an attractive hypothesis, are nothing more. Moreover Bridges' (36) work on triploidy shows that sex may be determined by other groups of factors than those which normally determine it. It seems possible then, that sex is normally determined, not by a specific factor, but by the simultaneous activity of a farly large group of factors, each of which has, or may have, other effects. The loss of any one member of this group will not cause a change of sex, thougn it may cause partial sterility. If sex were determined by a single factor it is very difficult to see what advantage there could be in its being linked with other factors. If on the other hand a number of factors determine it, it is essential that they should be linked. If in any inimals sex is determined by one factor, there is probably no sex-linkage or chromosome difference between the sexes. As soon as inother fictor becomes necessary, complete linkage between the two must appear in the heterozygous sex, and the sime mechanism which prevents them from crossing over may be expected to hinder or prevent crossing over of all factors in that sex.

I shall not attempt here to discuss the phenomena observed in the $F_{2}$ of the crosses considered. Their variability is partly explained by 


\section{Sex Ratio and Unisexual Sterility in Hybrid Animals}

the fact that the fertile $F_{1}^{*}$ may either be all homozygotes, or in part transformed heterozygotes, partly by failures in reduction.

It is worth noticing that other disturbing influences do not affect the heterozygous sex more than the homozygous. Thus late fertilization tums $X X$ frog zygotes into males, and the blood of their brothers converts $X X$ mammalian embryos into freemartins. On the other hand the distinction between homozygous and heterozygous sex is more fundamental than that between male and female in determining the intensity of partial linkage between factors. Obviously sex-linked factors must be completely linked in the heterozygous sex, but linkage between autosomal factors is also always stronger in that sex. In Drosophila melanogaster, simulans and virilis linkage is always complete in the heterozygous inale, in Bombyx, as shown by Tanaka(41), in the heterozygous female. Nabours(42) in Apotettix and Haldane(43) in Paratettix found linkage much stronger in the heterozygous male. And Dunn(44) showed that in the rat and mouse linkage is slightly stronger in the heterozygous male. If these facts are anything more than a coincidence they may be dne to a greatis. difficulty of fusion of chromosome pairs in the heterozygous sex, and this in turn may be a contributory cause of its sterility. A possible evolutionary explanation of this stronger linkage has been suggested above.

I wish to record my thanks to the Rev. E. Lewis Jones for his information concerning pheasant-poultry hybrids.

\section{Summary.}

When in the $F_{1}^{\prime}$ offspring of a cross between two animal species or races one sdx is absent, rare, or sterile, that sex is always the heterozygous sex.

\section{REFERENCES.}

1. Doncasten. The Determination of Sex, p. 87.

2. Gullummor. Ann. Soc. Entom. France, 1856, p. 29.

3. TUтr. British Lepidoptera, Vol. Iv. pp. 1-38.

4. CAster. Int. Ent. Zeit. Vol. Iv. p. 181, 1910.

5. Grosse. Int. Ent. Zeit. Vol. v. p. 327, 1912.

6. Standfuss. Proc. viI. Int. Zool. Congress, pp. 113-115, 1907.

7. NeUMÖGEN. Entom. News, Vol. v. p. 326, 1894.

8. Tux'r. British Lepidoptera, Vol. III. pp. 395, 448-459, 495.

9. Strandrosss. Bulll. Soc. Entom. France, 1901, pp. 87-89.

10. Dannenuelic. Zeit. Wiss. Insektenbiol. Vol. vill. p. 27, 1912, Vol. 1x. p. 294 , 1913. 
11. Aust'aut. Le Naturaliste. Vol. xiv. p. 236.

12. Standfuss. Handbuch der Palaearktische Grossschmetterlinge, pp. 54-117.

13. - Stett. Ent. Zeit. Vol. xLv. p. 193, 1895.

14. Harrison. Journal of Genetics, Vol. vi. p. 95, 1916.

15. _- Journal of Genetics, Vol. vI. p. 269, 1917.

16. - Journal of Geneties, Vol. Ix. p. 1, 1919.

17. - Journal of Geneties, Vol. Ix. p. 195, 1920.

18. _- Journal of Geneties, Vol. x. p. 61, 1920.

19. Turr. British Lepidoptera, Vol. v. p. 31.

20. Goldschmidt. Zeitseh. Ind. Abst. u. Ver. Vol. xxir. p. 1, 1920.

21. Fietd. Psyche, Vol. 21, p. 115, 1914.

22. Bacot. Ent. Record, Vol. xIv. p. 106, 1902, Vol. xv. p. 134, 1903.

23. FLE'TChen. Ent. Record, Vol. Iv. p. 304, 1893.

24. Whirman and Riddet. Carn. Inst. Wash. Prub. 257; Vol. Ir. 1919.

25. Smith and Haig-Thomas. Journal of Geneties, Vol. Inг. p. 39, 1913.

26. Guyer. Biol. Bull. Vol. xvi. p. 193, 1909.

27. Phildirs. Journ. Evep. Zool. Vol. xvi. p. 143, 1914.

28. SturTtevant. Genetics, Vol. v. p. 488, 1920, Vol. v. p. 179, 1921.

29. DetLIIfSEN. Carn. Inst. Wash. Pub. 205, 1914.

30. BoxD. Journal of Heredity, Vol. v. p. 189, 1914.

31. Imanow and Philmtohenko. Zeit. Ind. Abst. u. Ver. Vol. xvi. p. 1, 1916.

32. Ackermann. Thierbastarde.

33. Bufron. Histoire Naturelle, Oeuvres Complètes. Quadrupèdes, vi. 1787, p. 378.

34. Keilin and Nutrald, Parasitology, Vol. ir. p. 279.

35. Agar. Journal of Geneties, Vol. x. p. 303, 1920.

36. Bridges. Am. Nat. Vol. Lvi. p. 5l, 1922.

37. LyNch. Genetics, Vol. Iv. p. 501, 1919.

38. Bridges and Morgan. Carn. Inst. Wash. Publ. 278, p. 231, 1919.

39. Metz and Bridges. Proc. Nat. Ac. Sci. Vol. III. p. 673, 1917; Vol. vi. 1. 421, 1920.

40. Doncaster. The Determination of Sex, p. 48.

41. Tanaka. Trans. Sapporo Nat. Hist. Soc. Vol. v. 1914.

42. Nabours. Am. Nat. Vol. LIIf. p. 131, 1919.

43. HaLdane. Journal of Genetics, Vol. x. p. 47, 1920.

44. Dunn. Genetics, Vol. v. p. 325, 1919. 